\title{
Small interfering RNA targeting N-cadherin regulates cell proliferation and migration in enzalutamide-resistant prostate cancer
}

\author{
CHENG-HSIN LU ${ }^{1-3^{*}}$, CHUN-HSIEN WU ${ }^{2,4,5^{*}}$, PEI-FANG HSIEH ${ }^{2,6}$, CHEN-YU WU $^{2,7}$, \\ WADE WEI-TING KUO ${ }^{2,4}$, CHIEN-HUI OU ${ }^{8 *}$ and VICTOR CHIA HSIANG LIN ${ }^{2,7 *}$ \\ ${ }^{1}$ Division of Urology, Penghu Hospital, Penghu 880001; ${ }^{2}$ Division of Urology, Department of Surgery, E-Da Hospital; \\ ${ }^{3}$ Division of Urology, Department of Surgery, E-Da Cancer Hospital; ${ }^{4}$ Department of Chemical Engineering and \\ Institute of Biotechnology and Chemical Engineering, ${ }^{5}$ Department of Nursing, I-Shou University, Kaohsiung 824005; \\ ${ }^{6}$ Department of Medical Laboratory Science and Biotechnology, Chung-Hwa University of Medical Technology, \\ Tainan 717302; ${ }^{7}$ School of Medicine, College of Medicine, I-Shou University, Kaohsiung 824005; \\ ${ }^{8}$ Department of Urology, National Cheng Kung University Hospital, College of Medicine, \\ National Cheng Kung University, Tainan 704302, Taiwan, R.O.C.
}

Received July 26, 2021; Accepted November 3, 2021

DOI: $10.3892 / \mathrm{ol} .2022 .13210$

\begin{abstract}
Enzalutamide is one of the options for treating patients with castration-resistant or metastatic prostate cancer. However, a substantial proportion of patients become resistant to enzalutamide after a period of treatment. Cells in these tumors typically exhibit increased proliferative and migratory capabilities, in which $\mathrm{N}$-cadherin $(\mathrm{CDH} 2)$ appear to serve an important role. In the present study, by up- and downregulating the expression of $\mathrm{CDH} 2$, the possible effects of $\mathrm{CDH} 2$ on the prostate cancer cell line LNCaP were investigated. Male sex hormone-sensitive LNCaP cells treated with $10 \mu \mathrm{M}$ enzalutamide were named LNCaP enzalutamide-resistant (EnzaR) cells. Reverse transcription-PCR, western blotting and
\end{abstract}

Correspondence to: Professor Victor Chia Hsiang Lin, Division of Urology, Department of Surgery, E-Da Hospital, 1 Yida Road, Kaohsiung 824005, Taiwan, R.O.C.

E-mail: victorlin0098@gmail.com

Professor Chien-Hui Ou, Department of Urology, National Cheng Kung University Hospital, College of Medicine, National Cheng Kung University, 138 Shengli Road, Tainan 704302, Taiwan, R.O.C. E-mail: donou1969@yahoo.com.tw

*Contributed equally

Abbreviations: $\mathrm{CDH} 2, \mathrm{~N}$-cadherin; EnzaR, enzalutamide-resistant; siRNA, small interfering RNA; EMT, epithelial-mesenchymal transition; $\mathrm{PCa}$, prostate cancer; ADT, androgen deprivation therapy; CRPC, castration-resistant prostate cancer; $\alpha$-SMA, $\alpha$-smooth muscle actin; WB, western blotting

Key words: N-cadherin, enzalutamide resistance, prostate cancer, proliferation, migration immunofluorescence staining were used to measure CDH2, E-cadherin, $\alpha$-SMA, Snail and Slug expression. Transfection with the pCMV-CDH2 plasmid was performed for $\mathrm{CDH} 2$ upregulation, whilst transfection with small interfering RNA (siRNA)-CDH2 was performed for $\mathrm{CDH} 2$ downregulation. MTT and Cell Counting Kit-4 assays were used to evaluate the proportion of viable cancer cells. Subsequently, gap closure assay was performed to evaluate the migratory capability of both LNCaP and LNCaP EnzaR cell lines. CDH2 expression was found to be increased in LNCaP EnzaR cells compared with that in LNCaP cells. $\mathrm{CDH} 2$ overexpression increased cell viability and migration in both LNCaP and LNCaP EnzaR cell lines. By contrast, the opposite trend was observed after $\mathrm{CDH} 2$ expression was knocked down. $\mathrm{CDH} 2$ expression also showed a high association with that of four epithelial-mesenchymal transition markers, which was confirmed by western blotting. Based on these results, it was concluded that knocking down $\mathrm{CDH} 2$ expression using siRNA transfection mediated significant influence on LNCaP EnzaR cell physiology, which may be a potential therapeutic option for prostate cancer treatment.

\section{Introduction}

Prostate cancer ( $\mathrm{PCa}$ ) is one of the most prevalent malignancies in men, the severity of which is heterogeneous, ranging from indolent to lethal (1). The main therapeutic strategy for metastatic PCa and castration-naïve recurrence is androgen deprivation therapy (ADT) (2). By reducing androgen levels, ADT blocks the activation of the androgen signaling cascade and androgen receptor (AR)-mediated gene expression (3). However, after a period of ADT, evolution to castration-resistant prostate cancer (CRPC) frequently occurs (4). Treatment options for CRPC are limited, since the majority of the second-generation anti-androgen therapeutic 
agents target the AR (5). One option for treating this type of cancer is enzalutamide, which was approved by the Food and Drug Administration in 2018 (6). It is an AR antagonist that also blocks its nuclear translocation and AR-mediated DNA binding (7). Despite the availability of this second-generation anti-androgen, a proportion of tumors will develop resistance to enzalutamide (8). By investigating causes and characteristics underlying enzalutamide resistance in $\mathrm{PCa}$, novel therapeutic strategies can be discovered.

One reported cause of therapeutic resistance is epithelial-mesenchymal transition (EMT), which is a fundamental process of embryogenesis (9). Resistance to oxaliplatin has been previously found in colon carcinoma epithelial cell lines with mesenchymal morphology (10). In addition, loss of epithelial phenotype have also been reported to associate with resistance to paclitaxel in ovarian carcinoma epithelial cell lines (11). In a similar manner, EMT has been found to promote the conversion to androgen-independent PCa (12). EMT is also a key process in promoting cancer cell invasiveness, since it disrupts cell-to-cell or cell-to-extracellular matrix adherence (13). It serve a role in the metastasis of certain malignancies by inducing the loss of E-cadherin expression whilst increasing $\mathrm{N}$-cadherin expression (13). A number of factors have been documented to be involved in this mechanism (14). Snail, Slug and Twist are among the number of E-cadherin transcriptional repressors that can induce the epigenetic silencing of the E-cadherin promoter (14). Furthermore, $\alpha$-smooth muscle actin $(\alpha-$ SMA) is a myofibroblast marker that can be used as a marker of cancer-associated fibroblasts (15). $\alpha$-SMA-positive myofibroblasts can promote the metastasis of oral tongue squamous cell carcinoma cells by promoting EMT (15). Previous studies have also shown that regulating particular markers, such as Snail and Slug, may facilitate prostate cancer metastasis $(16,17)$.

Cadherin-2 (CDH2), also known as N-cadherin, is highly expressed in the nervous system and vascular endothelium (18). It is a member of the cadherin family and is involved in various intracellular signaling pathways, such as the PI3K/Akt signaling pathway $(19,20)$. It also serves an important role in EMT. CDH2 expression has been found to serve a role in several human cancers, including bladder, colorectal, lung and gastric cancer (20-23). Since it can weaken intercellular interactions and form homophilic interactions with other $\mathrm{CDH} 2$-expressing tissues, $\mathrm{CDH} 2$ has been shown to be a key component in mediating cancer cell invasion and metastasis $(24,25)$. In $\mathrm{PCa}, \mathrm{CDH} 2$ expression is typically higher in patients with high-grade primary tumors or lymph node metastasis compared with that in patients with low-grade tumors $(26,27)$. In addition, $\mathrm{CDH} 2$ expression was found to positively correlated with the Gleason score $(26,27)$. This increased $\mathrm{CDH} 2$ expression is sufficient for EMT as well as prostate cancer invasion and metastasis (25). Furthermore, it was found to be necessary for the proliferation of CRPC cells and causes CRPC development $(12,25)$. In a previous study performed by Tanaka et al (25), N-cadherin was present in a number of castration-resistant cell lines but was absent in the hormone-sensitive LNCaP cell line (25). The difference in molecular expression between castration-resistant and hormone-sensitive cell lines suggests $\mathrm{CDH} 2$ to be a possible target for CRPC treatment.
In the present study, two different prostate cancer cell lines, LNCaP and enzalutamide-resistant LNCaP cells ( LNCaP EnzaR cells), were chosen. Compared with LNCaP cells, LNCaP EnzaR cells display a similar morphology but heterogeneous proliferative characteristics (28). LNCaP EnzaR cells also display increased metastatic colonization potential in a number of clinically relevant organs in vivo, including bone, brain and the adrenal glands (28). By comparing the properties of these two cell lines, the aim was to explore a novel strategy to manipulate prostate cancer cell physiology. The expression levels of $\mathrm{CDH} 2$ in these two PCa cell lines were first measured. Subsequently, CDH2 expression was upregulated before assessing its possible effects on cell viability, migratory capability and the expression of EMT markers in LNCaP and LNCaP EnzaR cells. Finally, to investigate the influence of $\mathrm{CDH} 2$ on cell viability and migration, the same assays were performed on cells with LNCaP and LNCaP EnzaR cells transfected with small interfering RNA (siRNA)-CDH2 cells to downregulate $\mathrm{CDH} 2$.

\section{Materials and methods}

Cell culture. LNCaP cells were obtained from the American Tissue Culture Collection and cultured in RPMI-1640 medium (Gibco; Thermo Fisher Scientific, Inc.) supplemented with $10 \%$ FBS (Gibco; Thermo Fisher Scientific, Inc.) at $37^{\circ} \mathrm{C}$ with $5 \% \mathrm{CO}_{2}$. LNCaP cells were exposed to different concentrations of enzalutamide (1-10 $\mu \mathrm{M}$; cat. no. S1250; Selleck Chemicals). At each concentration of enzalutamide, the cells were grown in RPMI-1640 medium (Gibco; Thermo Fisher Scientific, Inc.) supplemented with $10 \%$ FBS (Gibco; Thermo Fisher Scientific, Inc.) under $5 \% \mathrm{CO}_{2}$ at $37^{\circ} \mathrm{C}$ for 1 week to allow them to acclimatize and then proliferate for $\mathrm{a} \geq 6$ months. Since there is no consensus on the concentrations required to generate EnzaR cells, the cells were treated under $5 \% \mathrm{CO}_{2}$ at $37^{\circ} \mathrm{C}$ with $10 \mu \mathrm{M}$ enzalutamide in accordance with previous studies $(28,29)$. The LNCaP EnzaR cells generated from $10 \mu \mathrm{M}$ enzalutamide treatment were maintained in the aforementioned media containing $5 \mu \mathrm{M}$ enzalutamide.

Transfection. To create the pCMV-CDH2 plasmid, the $\mathrm{CDH} 2$ (accessionno.NM_001792)openreading frame(ORF) sequence was cloned into the Human-Tagged ORF Clone plasmid (cat. no. RC207170; Origene Technologies, Inc.). Cells were cultured in six-well plates and treated with the pCMV-CDH2 (2 $\mu \mathrm{g} / \mathrm{ml}$ ) (cat. no. RC207170; Origene Technologies, Inc.) or pCMV-GFP plasmid ( $2 \mu \mathrm{g} / \mathrm{ml}$ ) (cat. no. PS100010; Origene Technologies, Inc.). Plasmid transfections were performed using FuGENE HD Transfection Reagent (Roche Diagnostics, Inc.) and incubated for $37^{\circ} \mathrm{C}$ and $5 \% \mathrm{CO}_{2}$ for $24 \mathrm{~h}$ according to the manufacturer's protocols. LNCaP and LNCaP EnzaR cell lines were each divided into the following three groups: Untreated cells (pCMV-GFP:-, pCMV-CDH2:-); empty vector-transfected cells (pCMV-GFP:+, pCMV-CDH2:-); and CDH2 transfected cells (pCMV-GFP:-, pCMV-CDH2:+).

For $\mathrm{CDH} 2$ knockdown, the $\mathrm{CDH} 2$ gene was silenced using ON-TARGETplus CDH2 siRNA SMARTpool (siRNA-CDH2; cat. no. L-011605-00-0005), which was purchased from Dharmacon, Inc.; Cytiva. The sequences of CDH2 siRNA and the ON-TARGETplus non-targeting pool (siRNA-control; 
Dharmacon, Inc.; Cytiva; cat. no. D-001810-10-05) are listed in Table I. CDH2 siRNAs (5 pmol) were transfected into the cells using Lipofectamine RNAiMAX reagent (Invitrogen; Thermo Fisher Scientific, Inc.) under 5\% $\mathrm{CO}_{2}$ at $37^{\circ} \mathrm{C}$ for $24 \mathrm{~h} . \mathrm{LNCaP}$ and $\mathrm{LNCaP}$ EnzaR cell lines were also divided into the following groups: Untreated cells (siRNA-control:-, siRNA-CDH2:-), siRNA-control-transfected cells (siRNA-control:+, siRNA-CDH2:-) and siRNA-CDH2transfected cells (siRNA-control:-, siRNA-CDH2:+).

After $24 \mathrm{~h}$ of transfection, the cells were subjected to reverse transcription PCR (RT-PCR) and western blot (WB) analysis.

$R T-P C R$. Total RNA was isolated using TRIzol reagent (Invitrogen; Thermo Fisher Scientific, Inc.). In total, $1 \mu \mathrm{g}$ total RNA was subjected to reverse transcription into cDNA using SuperScript $^{\mathrm{TM}}$ III First Strand Synthesis System for RT-PCR (Invitrogen; Thermo Fisher Scientific, Inc.). From $5 \mu \mathrm{g}$ RNA, cDNA was prepared using oligo dT $(50 \mu \mathrm{M})$ and $10 \mathrm{mM}$ dNTP. For the PCR reactions, $1 \mu \mathrm{l}$ oligo dT primer and $1 \mu \mathrm{l}$ $10 \mathrm{mM}$ dNTP mix were added to $8 \mu 1 \mathrm{RNA}$, incubated for $5 \mathrm{~min}$ at $65^{\circ} \mathrm{C}$ and then placed on ice for $\geq 1 \mathrm{~min}$. Subsequently, $10 \mu \mathrm{l}$ cDNA synthesis mix was added [2 $\mu \mathrm{l} 10 \mathrm{X}$ RT buffer, $4 \mu \mathrm{l}$ $25 \mathrm{mM} \mathrm{MgCl}, 2 \mu \mathrm{l} 0.1 \mathrm{M}$ DTT, $1 \mu \mathrm{l}$ RNase OUT ${ }^{\mathrm{TM}}$ (40 U/ $\mu \mathrm{l}$ ) and $1 \mu \mathrm{l}$ SuperScript ${ }^{\mathrm{TM}}$ III RT (200 U/ $\left.\mu \mathrm{l}\right)$ ] to each RNA/primer mixture and incubated for $50 \mathrm{~min}$ at $50^{\circ} \mathrm{C}$, followed by reaction termination at $85^{\circ} \mathrm{C}$ for $5 \mathrm{~min}$. For each reaction, 10X PCR buffer (cat. no. 18067-017; Invitrogen; Thermo Fisher Scientific, Inc.), $\mathrm{MgCl}_{2}$ (50 mM), dNTP mix (10 mM), cDNA, Taq DNA polymerase $(5 \mathrm{U} / \mu \mathrm{l})$ and each pair of primers were added. The resultant product was stored at $-20^{\circ} \mathrm{C}$. Reactions containing $5 \mu \mathrm{l}$ 10X PCR buffer, $1.5 \mu 150 \mathrm{mM} \mathrm{MgCl} 2,1 \mu 110 \mathrm{mM}$ dNTP mix, $2 \mu \mathrm{g}$ cDNA, $10 \mu \mathrm{M}$ of each pair of primers, $0.4 \mu \mathrm{l}$ Taq DNA polymerase and $38.1 \mu 1$ DEPC water were first incubated for initial denaturation at $94^{\circ} \mathrm{C}$ for $2 \mathrm{~min}$. PCR was then performed for 35 cycles. For all PCR programs, an annealing temperature of $55^{\circ} \mathrm{C}$ for $30 \mathrm{sec}$ and denaturation and extension temperatures of $94^{\circ} \mathrm{C}$ and $72^{\circ} \mathrm{C}$, respectively, for $30 \mathrm{sec}$.

RNA was used as a template for reverse transcription (Invitrogen; Thermo Fisher Scientific, Inc.) followed by PCR analysis using specific primers for $\mathrm{N}$-cadherin (forward, 5'-AGCCTGGAACATATGTGATGA-3' and reverse, 5'-CCA TAAAACGTCATGGCAGTAA-3'); GAPDH forward, 5'-ATGTGTCCGTCGTGGATCTGAC-3' and reverse, 5'-AGA CAACCTGGTCCTCAGTGTAG-3'. The expression levels of total RNA were normalized to the expression of gene GAPDH (assay ID, Hs03929097_g1; Thermo Fisher Scientific, Inc.). DNA $(0.5 \mu \mathrm{g} /$ lane $)$ was visualized using gel electrophoresis on a $2 \%$ agarose gel stained with SafeView ${ }^{\mathrm{TM}}$ Classic staining (Applied Biological Materials, Inc.).

$W B$. The cells were lysed using RIPA buffer $(50 \mathrm{mM}$ Tris/pH 7.4, $150 \mathrm{mM} \mathrm{NaCl}, 1 \%$ Triton $\mathrm{X}-100,1 \%$ sodium deoxycholate, $0.1 \%$ SDS, $1 \mathrm{mM}$ sodium orthovanadate, $1 \mathrm{mM}$ sodium fluoride and $1 \mathrm{mM}$ EDTA). A BSA standard curve was used to detect protein concentration, which was used to analyze cell lystates. Protein lysates $(20 \mu \mathrm{g})$ were separated by $10 \%$ SDS-PAGE and then transferred onto polyvinylidene fluoride membranes (EMD Millipore). After blocking the membranes with $5 \%$ non-fat milk for $1 \mathrm{~h}$ at $25^{\circ} \mathrm{C}$, they were 
incubated with 1:2,000 dilutions of specific primary antibodies against E-cadherin (CDH1; cat. no. ab53033; Abcam), CDH2 (cat. no. ab18203; Abcam), $\alpha$-SMA (cat. no. ab5694; Abcam), Snail (cat. no. ab85931; Abcam), Slug (cat. no. sc-166476; Santa Cruz Biotechnology, Inc.) and $\beta$-actin (cat. no. A5441; Sigma-Aldrich; Merck KGaA) at $4^{\circ}$ Covernight. The membranes were then washed in Tris-buffered saline with $0.1 \%$ Tween 20 and incubated with HRP-conjugated secondary antibodies (cat. no. ab6721; Abcam; 1:4,000) for $1 \mathrm{~h}$ at room temperature. The Pierce ${ }^{\mathrm{TM}}$ ECL Western Blotting Substrate enhanced chemiluminescence system (cat. no. 32209; Thermo Fisher Scientific, Inc.) was used for visualization and detection using a Multi-function Gel Image System (cat. no. MQIS-21-C2; Tangshan Top Bio Technology, Co., Ltd.).

Immunofluorescence staining. To perform immunocytochemistry analysis, $1 \times 10^{4}$ cells grown in two-well chamber slides were transfected and incubated for $24 \mathrm{~h}$ at $37^{\circ} \mathrm{C}$ in a humidified atmosphere with $5 \% \mathrm{CO}_{2}$. Cells were washed with PBS two times, fixed and permeabilized with $99.9 \%$ ice-cold methanol for $15 \mathrm{~min}$ at $4^{\circ} \mathrm{C}$ before blocking with $2 \% \mathrm{BSA}$ in PBS for $1 \mathrm{~h}$ at $4^{\circ} \mathrm{C}$. Cells were then incubated with primary antibodies against CDH2 (cat. no. ab18203; Abcam; 1:2,000) for $1 \mathrm{~h}$ at $4^{\circ} \mathrm{C}$, washed with PBS three times and incubated with Alexa Fluor $^{\circledR}$ 488-labeled, species-specific secondary antibodies (cat. no. ab150077; Abcam). Before mounting, the slides were washed with PBS, counterstained with $1.5 \mu \mathrm{g} / \mathrm{ml}$ DAPI for nuclear staining at room temperature for $1 \mathrm{~h}$ and then observed under a fluorescent microscope (Olympus Corporation; magnification, x200) using the ipwin32 (Image-Pro Plus version no. 6; Media Cybernetics, Inc.) software.

MTT assay. Cells were grown in RPMI containing 10\% FBS, which were then plated at a density of $5 \times 10^{4}$ cells/well in 24-well plates overnight and incubated with pCMV-CDH2 for $24 \mathrm{~h}$, each at $37^{\circ} \mathrm{C}$ and $5 \% \mathrm{CO}_{2}$. Cell viability was assessed using MTT assay. After transfection for $24 \mathrm{~h}$, MTT solution was added into each well and incubated for $3 \mathrm{~h}$. Then, $50 \mu \mathrm{l}$ $5 \mathrm{mg} / \mathrm{ml} \mathrm{MTT} \mathrm{solution} \mathrm{was} \mathrm{added} \mathrm{into} \mathrm{each} \mathrm{well} \mathrm{containing}$ $500 \mu \mathrm{l}$ medium and incubated at $37^{\circ} \mathrm{C}$ for $3 \mathrm{~h}$, followed by the addition of $500 \mu \mathrm{l}$ isopropyl alcohol to dissolve the reduced formazan product. The absorbance at $590 \mathrm{~nm}$ in each well was measured using a spectrophotometer (Sunrise-Basic; Tecan Group, Ltd.) before cell viability was examined. Values calculated represent the mean $\mathrm{OD}_{590} \pm \mathrm{SD}$ from $\geq$ three independent reaction wells.

Cell Counting Kit-8 (CCK-8) assay. Cells were seeded into 96 -well plates and allowed to grow to $60-75 \%$ confluence before treatment. Cells were then transfected with pCMV-GFP, siRNA-control, pCMV-CDH2 or siRNA-CDH2 in RPMI 1640 with $10 \% \mathrm{FBS}$ at $37^{\circ} \mathrm{C}$ for $24 \mathrm{~h}$. Cell viability was evaluated using the CCK8 assay (cat. no. ab228554; Abcam). Afterwards, the medium was aspirated, rinsed with PBS and treated with CCK-8 at $10 \mu \mathrm{l} /$ well for $2 \mathrm{~h}$ at $37^{\circ} \mathrm{C}$. Absorbance was measured at $450 \mathrm{~nm}$ using a spectrophotometer (Sunrise-Basic; Tecan Group, Ltd.). The percentage of LNCaP and LNCaP EnzaR cell viability in cell lines, as well as their transfected cell lines, was calculated using the following formula: Viability $(\%)=($ optical density of sample/optical density of control) x100.
Gap closure assay. Cell migration by LNCaP and LNCaP EnzaR cells was examined using a gap closure assay with ibidi Culture-Insert 2 Well system (Cat.No:80209, Ibidi, Gräfelfing, Germany) according to the manufacturer's protocols. Cells were seeded overnight at a concentration of $1.75 \times 10^{4} / 100 \mu \mathrm{l} /$ well in each individual compartment of the Ibidi culture insert. The culture plate was then filled with RPMI complete medium as previously described $(30,31)$, before the Ibidi culture inserts were removed. A live cell imaging light microscope (Leica AF 6000 LX; Leica Microsystems, GmbH; magnification, x200) was used to monitor and capture images of the cells at $0 \mathrm{~h}$ and after $24 \mathrm{~h}$ of incubation at $37^{\circ} \mathrm{C}$. For each image, areas between one side of the gap and the other were measured using Quantity One software (version 4.6.6; Bio-Rad Laboratories, Inc.). Migration rate was quantified by dividing the change in wound area by the time spent in migration and was expressed as a percentage. To quantify the effects of $\mathrm{CDH} 2$ overexpression or knockdown on migration, the percentage of gap closure after $24 \mathrm{~h}$ was analyzed.

Statistical analysis. Each experiment was performed $\geq$ three times and representative images are shown. The results were expressed as the mean \pm standard error of the mean (SEM). Statistical analyzes with GraphPad Prism 9 (GraphPad Software, Inc.) were performed using one-way ANOVA followed by Tukey's post hoc test as appropriate. $\mathrm{P}<0.05$ was considered to indicate a statistically significant difference.

\section{Results}

CDH2 expression is increased in LNCaP EnzaR cells. To determine the role of $\mathrm{CDH} 2$ in $\mathrm{LNCaP}$ and $\mathrm{LNCaP}$ EnzaR cells, RT-PCR was used to first measure the expression levels of $\mathrm{CDH} 2$. $\mathrm{CDH} 2$ expression was markedly higher in the LNCaP EnzaR cell line, which was almost absent in the sensitive LNCaP cell line (Fig. 1A). Protein expression of $\mathrm{CDH} 2$ was next evaluated by $\mathrm{WB}$, where markedly higher $\mathrm{CDH} 2$ expression levels were also observed in LNCaP EnzaR cells compared with those in LNCaP cells (Fig. 1B). In addition, immunofluorescence staining revealed high $\mathrm{CDH} 2$ protein expression levels in LNCaP EnzaR cells, suggesting that LNCaP EnzaR cells express $\mathrm{CDH} 2$ at higher levels compared with that in LNCaP cells (Fig. 1C). $\mathrm{CDH} 2$ was found to be localized at the surfaces of LNCaP EnzaR cells, but exhibited low expression levels in the hormone-sensitive LNCaP cells according to immunostaining (Fig. 1C). These observations suggest that the expression of $\mathrm{CDH} 2$ is increased during the development of enzalutamide resistance.

CDH2 overexpression increases LNCaP and LNCaP EnzaR cell viability. To evaluate the effects of $\mathrm{CDH} 2$ on prostate cancer cells, MTT and CCK- 8 assays were used to measure cell viability. pCMV-CDH2 plasmid transfection efficiency was confirmed by RT-PCR, which markedly increased $\mathrm{CDH} 2$ expression in both LNCaP and LNCaP EnzaR cells compared with that in cells transfected with the empty vector (Fig. S1A).

In the LNCaP cell line, the pCMV-CDH2-transfected cells exhibited the highest levels of cell viability compared with those in the other two control groups $24 \mathrm{~h}$ after transfection, according to results from MTT assay (Fig. 2). A similar result 
A

RT-PCR

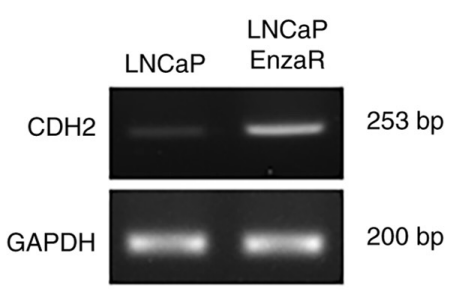

C

Immunofluorescence stain

LNCaP

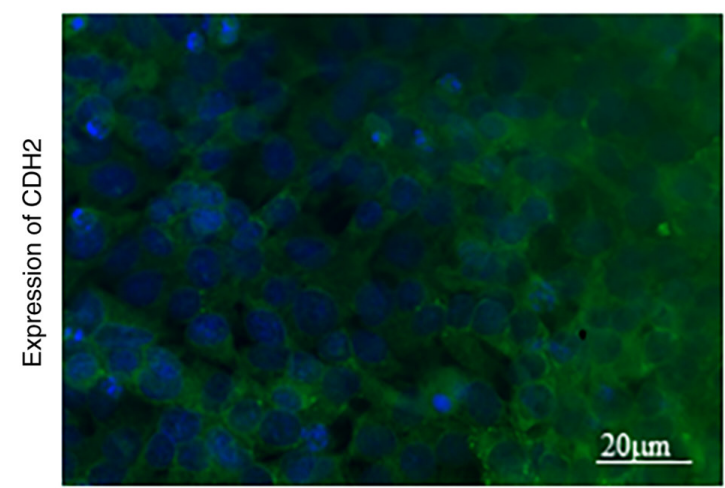

B

Westem blot

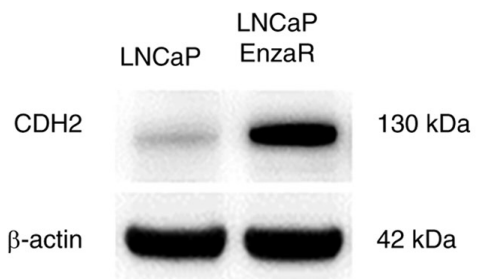

LNCaP

EnzaR

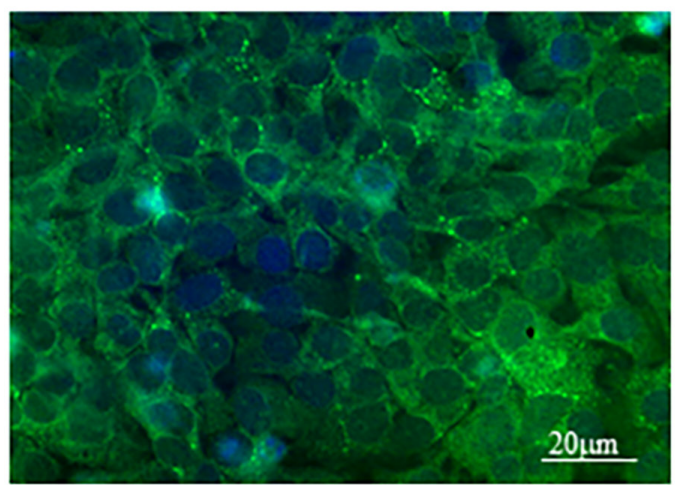

Figure 1. Expression of $\mathrm{CDH} 2$ in human PCa cell lines. $\mathrm{CDH} 2$ expression was higher in the LNCaP EnzaR cell line compared with that in the LNCaP cell line. (A) RT-PCR analysis of total RNA isolated from LNCaP and LNCaP EnzaR cells. GAPDH served as a loading control. (B) Protein expression of CDH2 in LNCaP and LNCaP EnzaR cells. $\beta$-actin served as a loading control. (C) Immunofluorescence assay was used to measure $\mathrm{CDH} 2$ expression in $\mathrm{LNCaP}$ and LNCaP EnzaR cells. Scale bars, $20 \mu \mathrm{m}$. CDH2, N-cadherin; PCa, prostate cancer; EnzaR, enzalutamide-resistant; RT, reverse transcription.
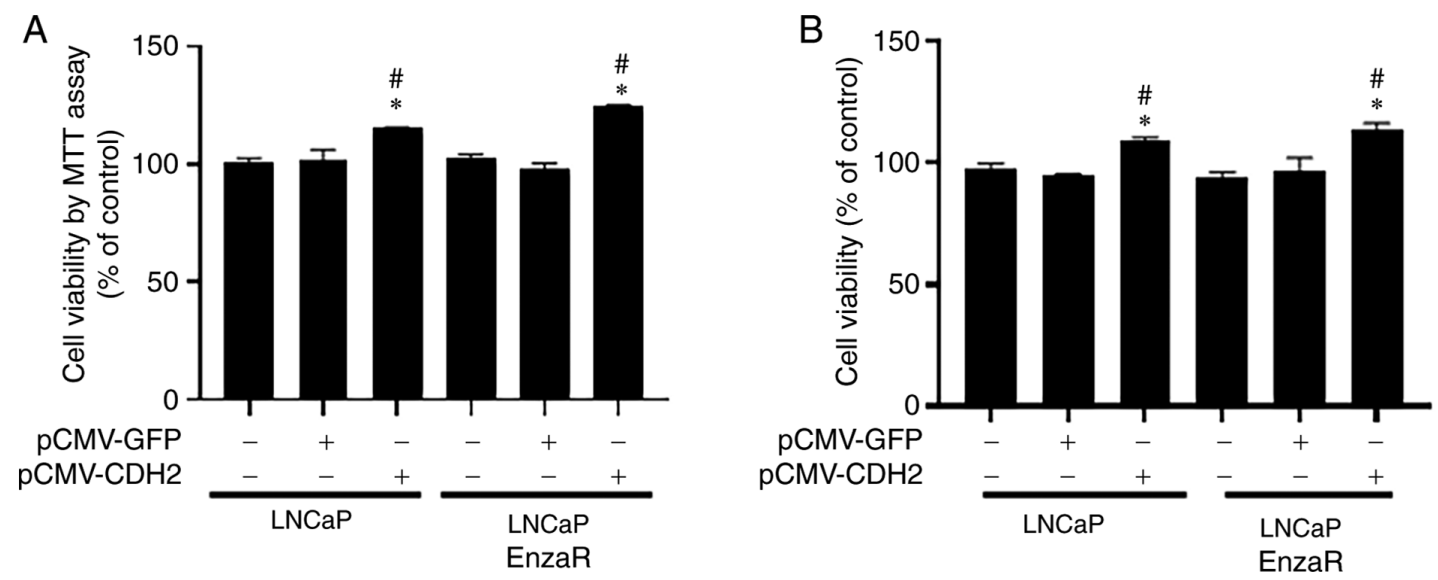

Figure 2. Overexpression of $\mathrm{CDH} 2$ increases $\mathrm{LNCaP}$ and $\mathrm{LNCaP}$ EnzaR cell viability. The OD values are expressed as a percentage of the total number of cells. (A) Cell viability increased significantly in both cell lines overexpressing CDH2 as observed by MTT assay. (B) LNCaP and LNCaP EnzaR cells overexpressing $\mathrm{CDH} 2$ also showed increased cell viability. ${ }^{*} \mathrm{P}<0.05$ vs. Control and ${ }^{\#} \mathrm{P}<0.05$ vs. pCMV-GFP. CDH2, N-cadherin; PCa, prostate cancer; EnzaR, enzalutamide-resistant; GFP, green fluorescent protein.

was observed in the LNCaP EnzaRA cell line (Fig. 2A). Cell viability was next assessed in the both $\mathrm{LNCaP}$ and $\mathrm{LNCaP}$ EnzaR cell lines using CCK-8 assay. Cells overexpressing $\mathrm{CDH} 2$ also showed the highest levels of cell viability in both $\mathrm{LNCaP}$ and LNCaP EnzaR cell lines compared with those in the other two control groups $24 \mathrm{~h}$ after transfection (Fig. 2B). These results suggest that $\mathrm{CDH} 2$ overexpression can increase PCa cell viability.

CDH2 overexpression increases LNCAP and LNCAP EnzaR cell migration. Ibidi gap closure assays were performed to examine the cell migratory capacity after transfection. After $24 \mathrm{~h}$ of transfection, the migration capacity of untreated $\mathrm{LNCaP}$ and LNCaP EnzaR cells was similar to that of empty vectortransfected cells. However, pCMV-CDH2-transfected cells showed a significantly increase in the capacity to migrate towards the center of the well compared with that in cells transfected with the empty vector (Fig. 3). These results were observed in both the LNCaP and LNCaP EnzaR cell lines (Fig. 3).

EMT is known to be associated with cancer cell invasion and migration (13). To clarify the mechanism underlying the increase in cell migration after transfection with 

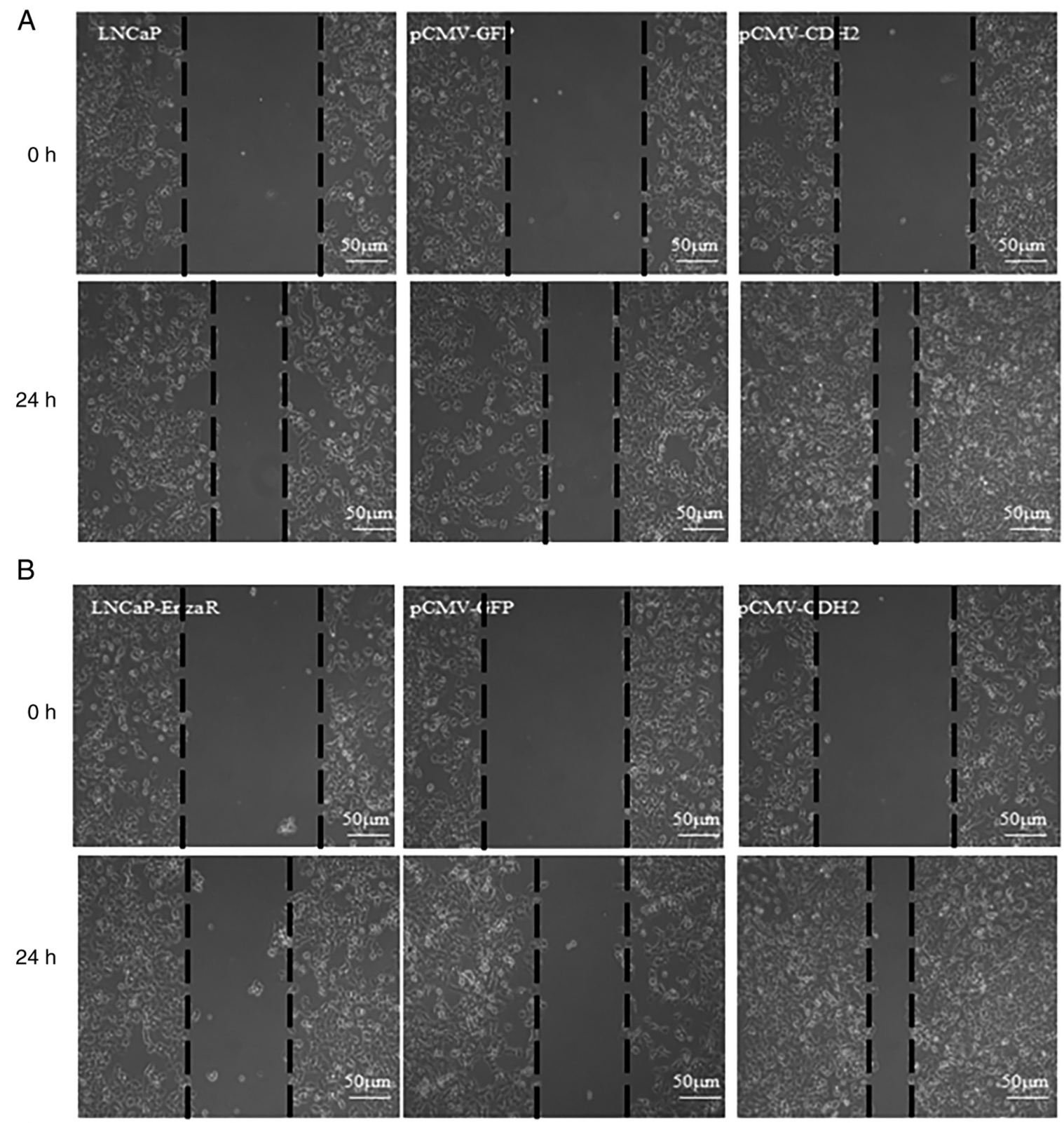

C
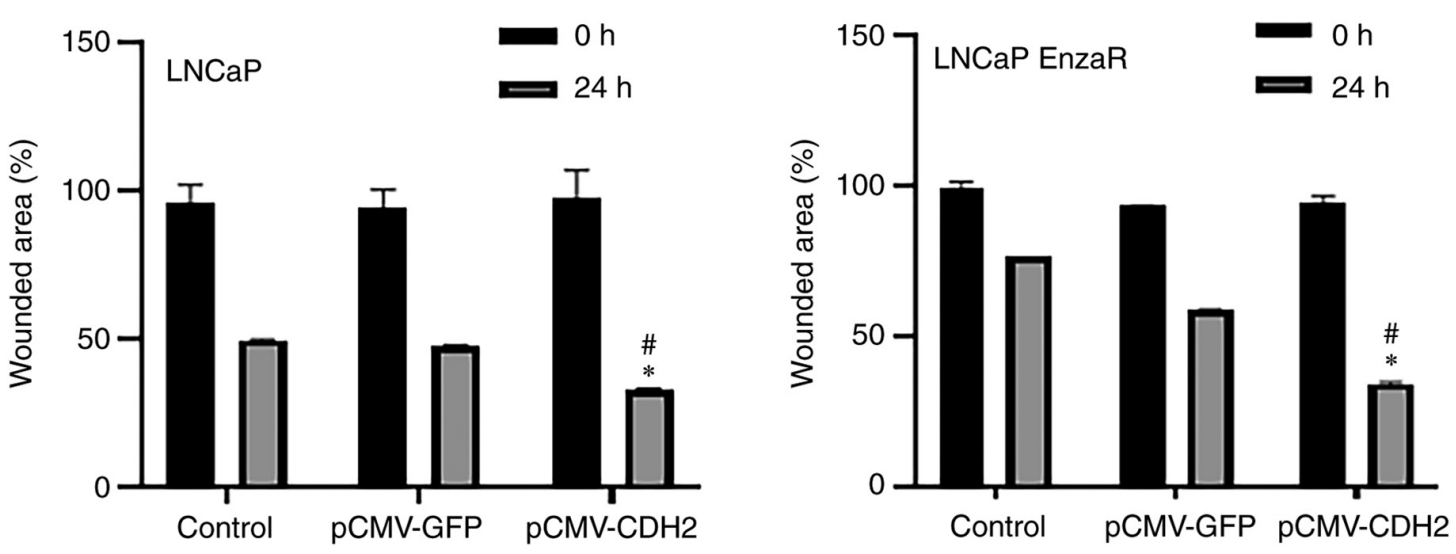

Figure 3. $\mathrm{CDH} 2$ overexpression increases LNCaP and LNCaP EnzaR cell migration. Ibidi insert gap closure assays were performed in (A) LNCaP and (B) LNCaP EnzaR cells, (C) which were also quantified. The initial $0 \mathrm{~h}$ area was used as a $100 \%$ control. Scale bars, $50 \mu \mathrm{m}$. ${ }^{*} \mathrm{P}<0.05$ vs. Control; and ${ }^{\#} \mathrm{P}<0.05$ vs. pCMV-GFP. CDH2, N-cadherin; EnzaR, enzalutamide-resistant; GFP, green fluorescent protein.

pCMV-CDH2, WB was used to measure the expression of EMT markers E-cadherin, $\alpha$-SMA, Snail and Slug. $\alpha$-SMA, Snail and Slug expression are positively correlated, whilst
E-cadherin expression is negatively correlated with EMT (13). The expression pattern of these four markers in untreated cells was similar to that in empty vector-transfected cells, which 
A

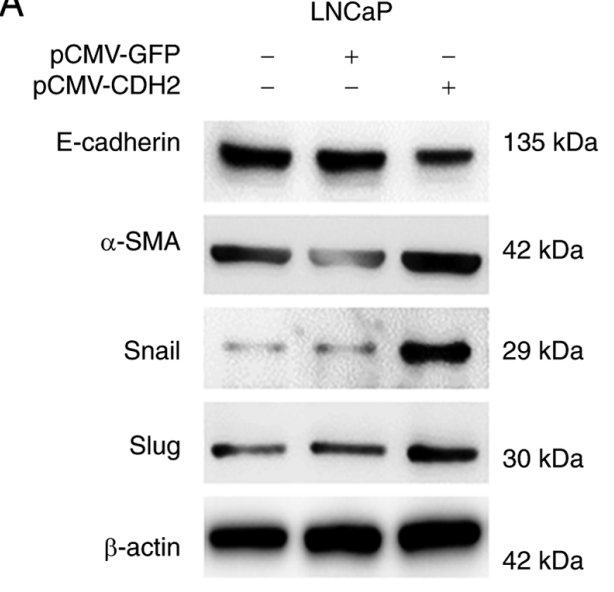

B

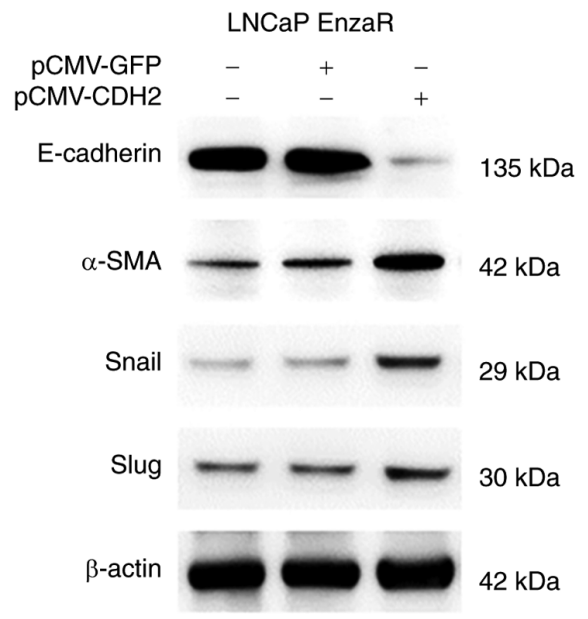

\section{LNCaP}

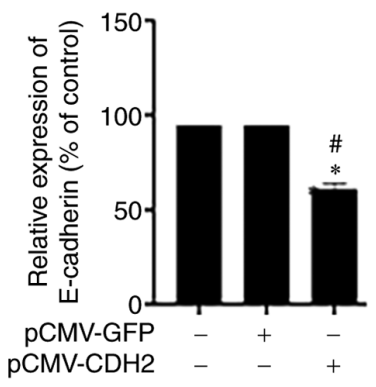

LNCaP EnzaR

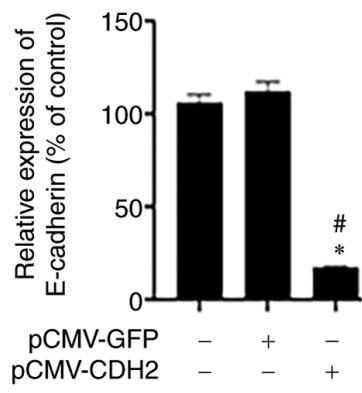

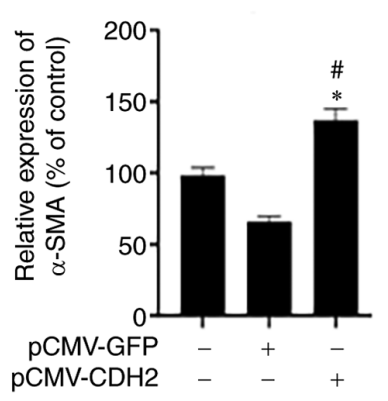

pCMV-GFP
pCMV-CDH2
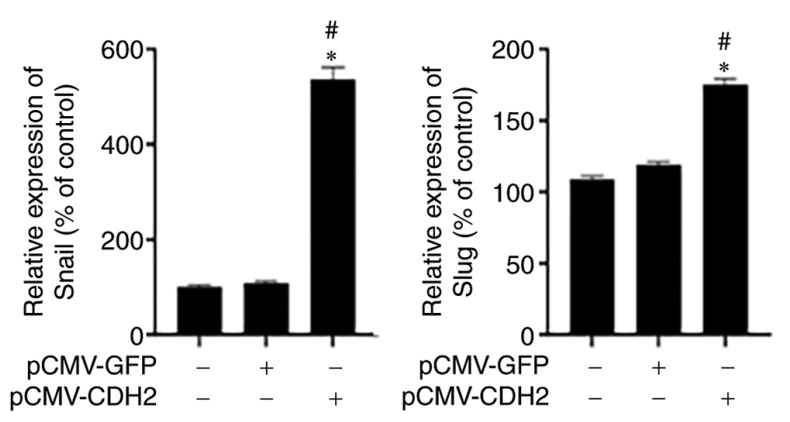
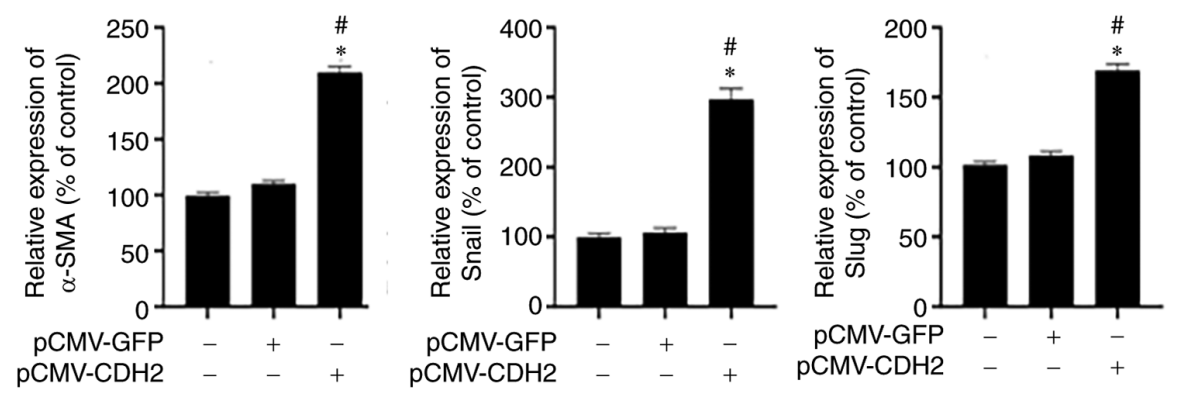

Figure 4. Measurement of EMT markers in LNCaP and LNCaP EnzaR cells overexpressing CDH2. Western blot analysis measuring E-cadherin, $\alpha$-SMA, Snail and slug expression in (A) LNCaP cells and (B) LNCaP EnzaR cells. Transfection with pCMV-CDH2 may increase EMT but not in cells transfected with pCMV-GFP. (C) The expression of E-cadherin was significantly decreased whereas that of $\alpha$-SMA, Snail and Slug was significantly increased in both cell lines overexpressing CDH2 compared with those in cells transfected with pCMV-GFP. "P<0.05 vs. Control; and "P<0.05 vs. pCMV-GFP. EMT, epithelial-mesenchymal transition; CDH2, N-cadherin; $\alpha$-SMA, $\alpha$-smooth muscle actin; EnzaR, enzalutamide-resistant; GFP, green fluorescent protein.

possibly explains the similar cell migratory capacities between these two groups of cells. In pCMV-CDH2-transfected LNCaP and LNCaP EnzaR cells, E-cadherin was significantly downregulated, whilst the other three markers were significantly upregulated (Fig. 4). This suggests that $\mathrm{CDH} 2$ overexpression may induce EMT in LNCaP and LNCaP EnzaR cells, which may be the reason why pCMV-CDH2-transfected cells exhibited the highest cell migration levels. These results suggest that $\mathrm{CDH} 2$ overexpression can promote EMT to increases the migratory capacity of PCa cells.

CDH2 knockdown reduces LNCaP and LNCaP EnzaR cell viability. After overexpression, the possible effects of CDH2 knockdown on PCa cells were evaluated. MTT and CCK-8 assays were performed to measure cell viability. siRNA-CDH2 transfection was used to knock down CDH2 expression. siRNA-CDH2 transfection efficiency in LNCaP and LNCaP EnzaR cells was verified using RT-PCR, which markedly reduced $\mathrm{CDH} 2$ expression compared with that in cells transfected with siRNA-control (Fig. S1). In terms of the LNCaP cell line, siRNA-CDH2-transfected cells exhibited the lowest levels of cell viability compared with that of the untreated cells and cells transfected with the siRNA-control according to MTT assay (Fig. 5A). In addition, cell viability was significantly reduced by siRNA-CDH2 transfection in the LNCaP EnzaR cell line (Fig. 5A). Similar results were observed according to CCK-8 assay. Specifically, siRNA-CDH2-transfected cells showed the lowest cell viability in both LNCaP and LNCaP EnzaR cells compared with that of the untreated cells and cells transfected with the siRNA-control (Fig. 5B). These results suggest that $\mathrm{CDH} 2$ knockdown using siRNA reduced PCa cell viability. 

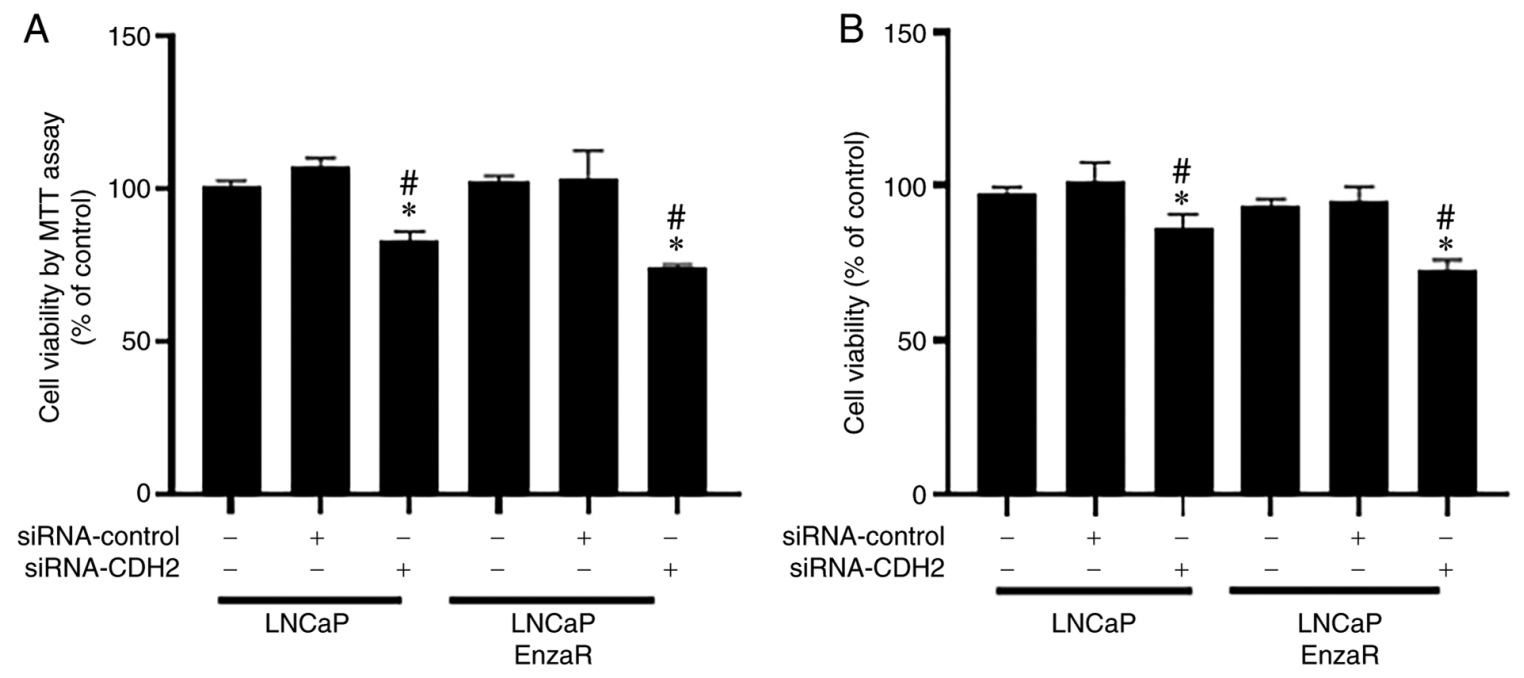

Figure 5. CDH2 knockdown reduces LNCaP and LNCaP EnzaR cell viability. The OD values of MTT and CCK-8 assays are expressed as percentages of the total number of cells. (A) After transfection with siRNA-CDH2, LNCaP cell viability was significantly decreased as according to results from MTT assay. (B) Cell viability was also reduced after transfection with siRNA-CDH2 according to results from CCK-8 assays. ${ }^{*} \mathrm{P}<0.05$ vs. Control; and ${ }^{\#} \mathrm{P}<0.05$ vs. siRNA-control. CDH2, N-cadherin; CCK-8, cell counting kit-8; siRNA, small interfering RNA; EnzaR, enzalutamide-resistant.

CDH2 knockdown inhibits LNCaP and LNCaP EnzaR cell migration. According to the Ibidi gap closure assay, it was observed that the level of migration in $\mathrm{LNCaP}$ cells transfected with the siRNA-CDH2 was significantly slower compared with that in untreated cells and cells transfected with the siRNA-control after $24 \mathrm{~h}$ (Fig. 6A and C). Similar findings were made regarding the levels of LNCaP EnzaR cell migration after $24 \mathrm{~h}$ (Fig. 6B and C).

To assess the association between decreased migration capacity and EMT, the protein expression of E-cadherin, $\alpha$-SMA, Snail and Slug was measured in both $\mathrm{LNCaP}$ and LNCaP EnzaR cells by WB. Consistent with this hypothesis, cells with $\mathrm{CDH} 2$ expression knocked down appeared to exhibit reduced EMT induction. Specifically, in siRNA-CDH2-transfected $\mathrm{LNCaP}$ and $\mathrm{LNCaP}$ EnzaR cells, E-cadherin expression was significantly increased, whilst the expression of $\alpha$-SMA, Snail and Slug was significantly decreased compared with that in untreated cells and cells transfected with the siRNA-control (Fig. 7). These results suggest that $\mathrm{CDH} 2$ knockdown can inhibit EMT and EMT-related protein expression to suppress PCa cell migration.

\section{Discussion}

In the present study, it was found that $\mathrm{CDH} 2$ was expressed at higher levels in LNCaP EnzaR cells compared with that in LNCaP cells in vitro. This finding is not unexpected, because $\mathrm{CDH} 2$ expression has been previously reported to be increased in poorly differentiated PCa and positively correlate with the Gleason score $(26,27,32)$. Similar observations in terms of the difference in $\mathrm{CDH} 2$ expression were obtained by Tanaka et al (25) Jennbacken et al (33) and Nalla et al (34), where androgen-dependent cell lines (LNCaP and LAPC4-AD) and androgen-independent cell lines (LNCaP-19, PC-3 and LAPC4-CR) were assessed.

In terms of cell viability, increased viability was noted after $\mathrm{CDH} 2$ overexpression, whereas the opposite was observed after siRNA-CDH2 transfection. This suggests that
$\mathrm{CDH} 2$ exerts a key influence on PCa cell survival and proliferation. A similar finding was reported in a previous study by Gao et al (35), where microRNA-194 overexpression, which targeted $\mathrm{CDH} 2$, was used to regulate $\mathrm{PCa}$ cells to reduce cell viability whilst increasing the rate of apoptosis (35). In addition, Wang et al (36) performed colony formation assays to explore the effect of $\mathrm{CDH} 2$ on the proliferation of $\mathrm{PCa}$ cells and demonstrated a positive association between $\mathrm{CDH} 2$ expression and PCa cell proliferation (36). Tanaka et al (25) also previously showed that N-cadherin-positive LAPC9 cells tended to proliferate more rapidly compared with that in N-cadherin-negative cells (25). The RAS/Raf signaling cascade following the cross-talk of $\mathrm{CDH} 2$ with other membrane proteins, such as integrins, may be the cause of tumor cell proliferation (37). However, the underlying mechanism of this was not evaluated in the present study.

Cancer metastasis is a process that requires multiple steps, with migration being a key step (38). In the present study, $\mathrm{CDH} 2$ expression in LNCap cells was found to be associated with cell migration. Using overexpression and gene silencing methods to manipulate $\mathrm{CDH} 2$ expression, LNCap and LNCap EnzaR cells with higher $\mathrm{CDH} 2$ expression were found to have higher migratory capabilities. In previous studies, $\mathrm{CDH} 2$ has been frequently reported as a factor that can promote liver, lung, bladder, renal, colorectal, breast, prostate and brain cancer cell migration and metastasis $(25,33,36,37)$. The Rac signaling pathway was found to be one of the underlying mechanistic causes (37). Furthermore, EMT has been found to be highly associated with cell migration (13). Several signaling pathways, including Wnt/ $\beta$-catenin, PI3K/AKT, T-cell factor/lymphoid enhancer-binding factor and RhoA, can become activated following cadherin switching (39-43). Crosstalk between these signaling pathways can increase the expression of a number of EMT transcription factors, including Snail, Slug and Twist (39). The increase of EMT transcription factor expression was previously demonstrated in $\mathrm{PC} 3, \mathrm{LNCaP}$ and DU145 cell lines (17,44-45). After determining the interaction between transcription factors, $\mathrm{CDH} 2$, EMT and cancer 
A

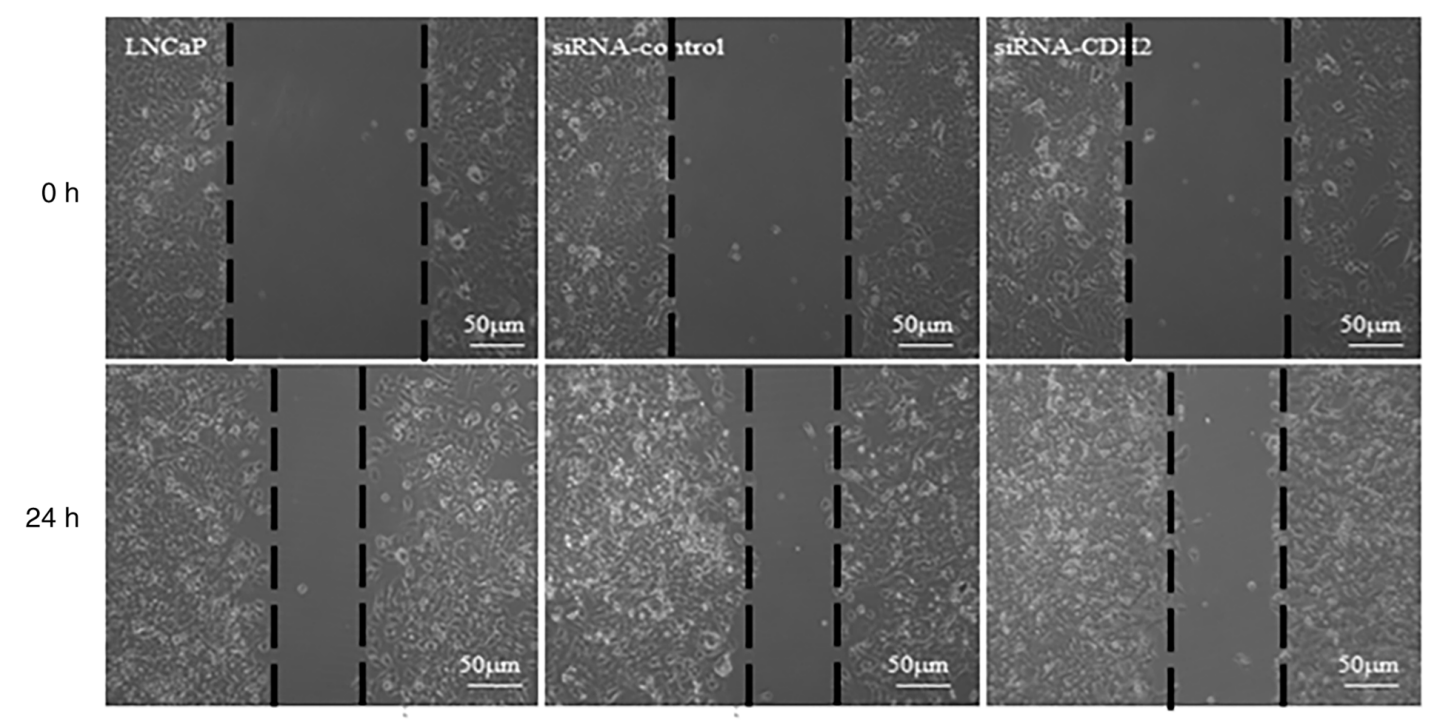

B
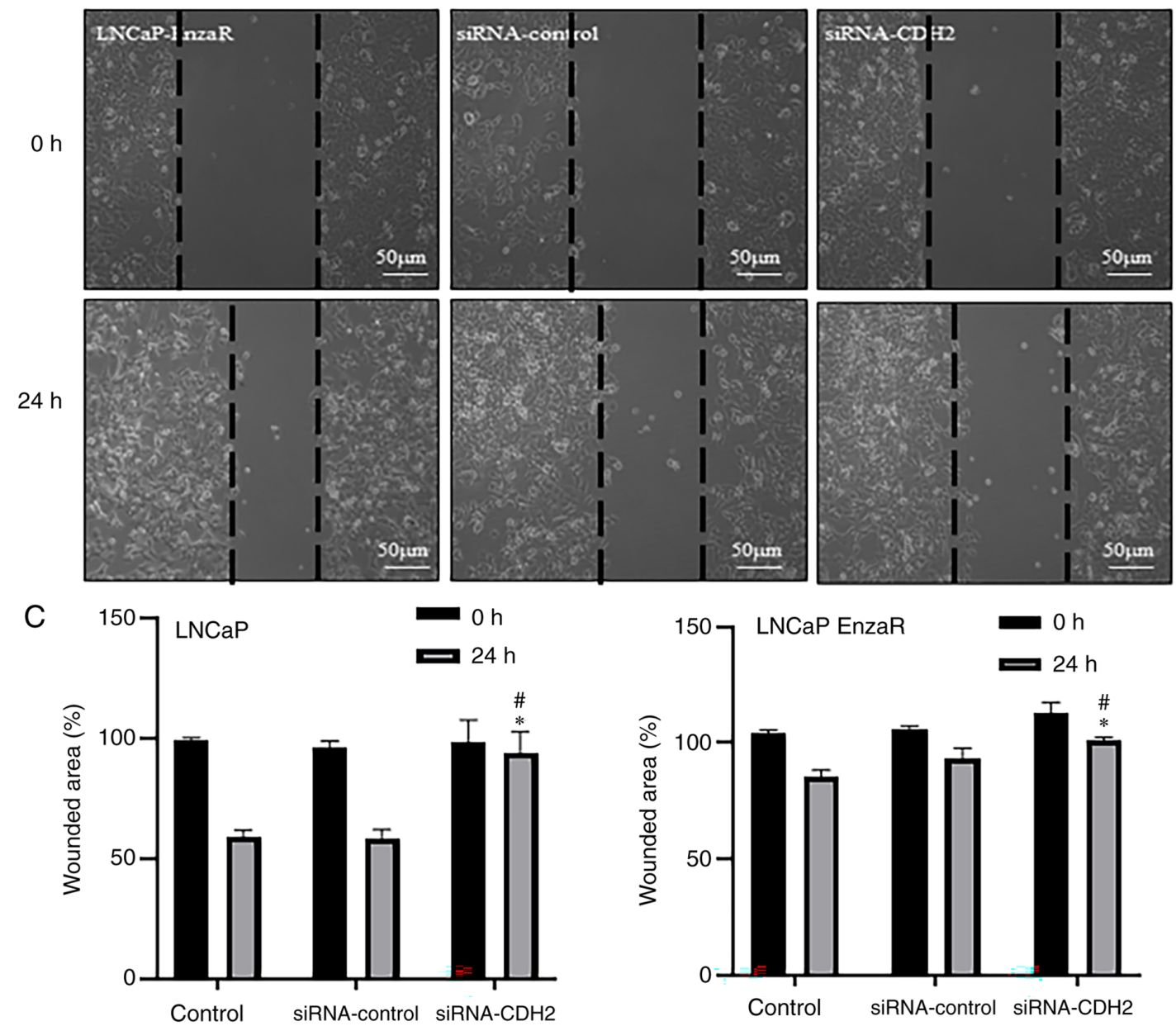

Figure 6. Knocking down CDH2 expression inhibits LNCaP and LNCaP EnzaR cell migration. After transfection with siRNA-CDH2, images were obtained at 0 and $24 \mathrm{~h}$ after wounding. Ibidi insert gap closure assay was performed in (A) LNCaP and (B) LNCaP EnzaR cells, (C) which were then quantified. The $0 \mathrm{~h}$ area was used as a $100 \%$ control. Scale bars, $50 \mu \mathrm{m}$. ${ }^{*} \mathrm{P}<0.05$ vs. Control; and ${ }^{\#} \mathrm{P}<0.05$ vs. siRNA-control. CDH2, N-cadherin; siRNA, small interfering RNA; EnzaR, enzalutamide-resistant.

cell migration, a possible connection was found between EMT and PCa cell migration by measuring the expression levels of these transcription factors following $\mathrm{CDH} 2$ regulation in the present study.
A number of factors and compounds that can target EMT have been previously demonstrated to modulate PCa cells. Li et al (46) found that resveratrol can reverse EMT through the Hedgehog pathway in PCa (46). In addition, 
A

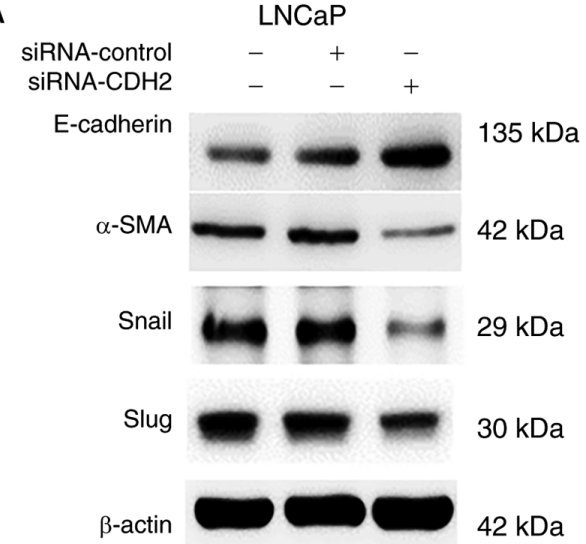

B

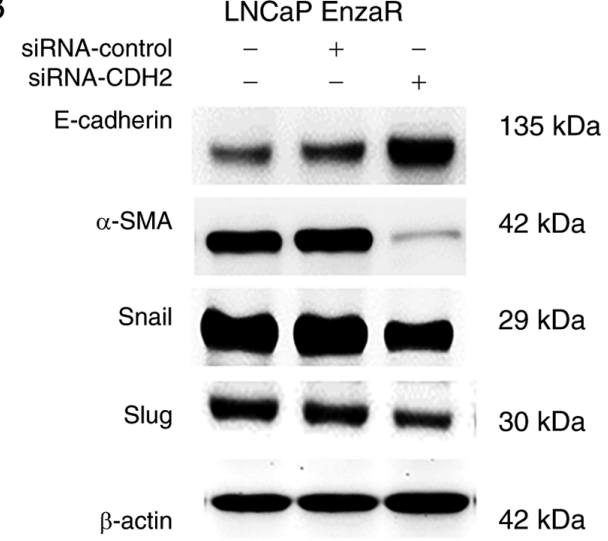

C

LNCaP
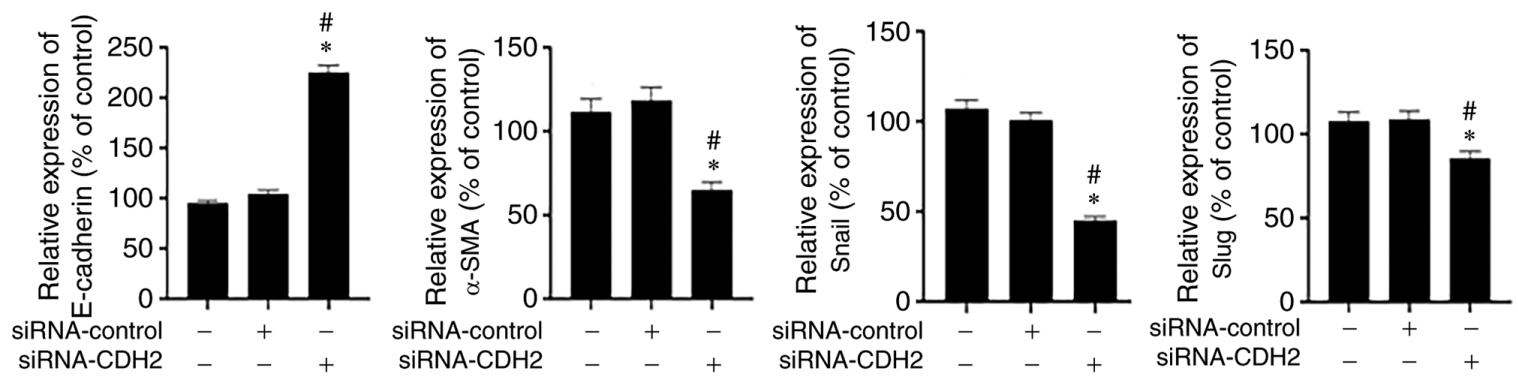

LNCaP EnzaR
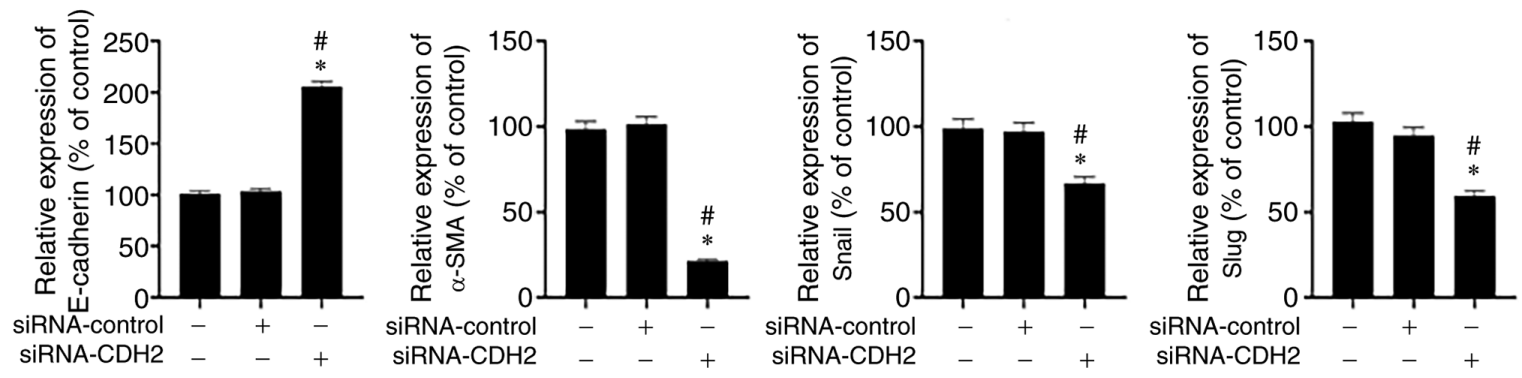

Figure 7. Measurement of epithelial-mesenchymal transition markers in PCa cells with CDH2 knockdown. Western blot analysis measuring E-cadherin, $\alpha$-SMA, Snail and slug expression in (A) LNCaP cells and (B) LNCaP EnzaR cells, (C) which were then quantified. $\alpha$-SMA, Snail and slug protein expression in cells transfected with siRNA-CDH2 was reduced, whereas E-cadherin expression was increased compared with that in cells transfected with siRNA-control or the control group. " $\mathrm{P}<0.05$ vs. Control; and ${ }^{~} \mathrm{P}<0.05$ vs. siRNA-control. PCa, prostate cancer; $\mathrm{CDH} 2, \mathrm{~N}$-cadherin; $\alpha$-SMA, $\alpha$-smooth muscle actin; EnzaR, enzalutamide-resistant; siRNA, small interfering RNA

curcumin was found to inhibit PCa cell EMT and invasion through the monoamine oxidase A/mTOR/hypoxia-inducible factor-1 $\alpha$ signaling pathway (47). MicroRNAs are short, non-coding and single-stranded RNA molecules that have been previous assessed as a potential biomarker in many types of cancer, where they serve a key regulatory functions in PCa progression $(48,49)$. MicroRNA-205, microRNA-143, microRNA-145 have been found to inhibit the EMT process by negatively regulating the expression of several transcription factors (50). Another possible target for $\mathrm{PCa}$ inhibition is $\mathrm{CDH} 2$. Using overexpression and knockdown approaches, Tanaka et al (25) were able to regulate $\mathrm{CDH} 2$ expression in the presence or absence of monoclonal $\mathrm{CDH} 2$ antibodies and determine its involvement in PCa. After monoclonal antibody inhibition, decreased cell proliferation and invasion in vitro and decreased growth and metastasis in vivo were observed (25). Similarly, the present study demonstrated that siRNA-CDH2 transfection reduced cell viability and migration in both LNCaP and LNCaP EnzaR cells in vitro. To the best of our knowledge, the present study is also the first to use siRNA for the downregulation of $\mathrm{CDH} 2$ expression in EnzaR PCa cells.

The present study is a preliminary study. Therefore, there are a number of limitations. Unlike other studies that used a panel of PCa cell lines, only LNCaP cells were used whereas its subline, LNCaP EnzaR, were used for examination. Furthermore, only in vitro experiments were performed to observe the effect of $\mathrm{CDH} 2$ knockdown. Since no in vivo experiments were performed, the precise mechanism underlying the effects of $\mathrm{CDH} 2$ knockdown on prostate tissues could not be verified. The only conclusion that can be drawn from the present study was that PCa cell migration, one of the key steps of metastasis, was impaired as a result of $\mathrm{CDH} 2$ knockdown. To further understand the effect of $\mathrm{CDH} 2$ knockdown on metastasis, invasion and the extent of mesenchymal-epithelial transition should be examined. In addition, 
results in the present study showed that $\mathrm{CDH} 2$ expression is positively associated with PCa cell viability, proliferation, migration and EMT. Further studies are warranted to determine the underlying mechanisms. Subsequent experiments should be focused on treating different PCa cell lines and in in vivo animal models.

According to the present study, it was demonstrated that EMT served an important role in modulating PCa cell proliferation and migration. In addition, the expression of $\mathrm{CDH} 2$, which significantly influences EMT, could be manipulated to reduce $\mathrm{PCa}$ cell viability and migration. These findings raise the possibility that $\mathrm{CDH} 2$ may be key to controlling CRPC and can be exploited in clinical practice.

\section{Acknowledgements}

The authors would like to thank Dr See-Tong Pang (Department of Uro-Oncology, Chang Gung Memorial Hospital, Taiwan), for providing the Enzalutamide-resistant LNCaP cells.

\section{Funding}

The present study was supported by E-Da Hospital Research (grant no. NCKUEDA10906) and National Science Council Grants, Taiwan (grant no. MOST 109-2314-B-650-013-MY2).

\section{Availability of data and materials}

The datasets used and/or analyzed during the current study are available from the corresponding author upon reasonable request.

\section{Authors' contributions}

VCHL and CHO conceived and designed the study. CHL and $\mathrm{CHW}$ were the major contributors in writing the manuscript. CHL and PFH analyzed and interpreted the data. CHW, PFH, CYW and WWTK performed the literature review and conducted the experiments. All authors read and approved the final manuscript. VCHL, CHO, CHL and $\mathrm{CHW}$ confirm the authenticity of all the raw data.

\section{Ethics approval and consent to participate}

Not applicable.

\section{Patient consent for publication}

Not applicable.

\section{Competing interests}

The authors declare that they have no competing interests.

\section{References}

1. Cooperberg MR, Cowan J, Broering JM and Carroll PR High-risk prostate cancer in the United States, 1990-2007. World J Urol 26: 211-218, 2008.
2. Pagliarulo V, Bracarda S, Eisenberger MA, Mottet N, Schröder FH, Sternberg CN and Studer UE: Contemporary role of androgen deprivation therapy for prostate cancer. Eur Urol 61: 11-25, 2012.

3. Liu T, Wu LY, Fulton MD, Johnson JM and Berkman CE: Prolonged androgen deprivation leads to downregulation of androgen receptor and prostate-specific membrane antigen in prostate cancer cells. Int J Oncol 41: 2087-2092, 2012.

4. Chandrasekar T, Yang JC, Gao AC and Evans CP: Mechanisms of resistance in castration-resistant prostate cancer (CRPC). Transl Androl Urol 4: 365-380, 2015.

5. Teo MY, Rathkopf DE and Kantoff P: Treatment of advanced prostate cancer. Annu Rev Med 70: 479-499, 2019.

6. FDA approves enzalutamide for castration-resistant prostate cancer. Available at: https://www.fda.gov/drugs/resourcesinformation-approved-drugs/fda-approves-enzalutamide-castration-resistant-prostate-cancer. Accessed December 1, 2021.

7. Wengner AM, Scholz A and Haendler B: Targeting DNA damage response in prostate and breast cancer. Int J Mol Sci 21: 8273, 2020.

8. Beer TM, Armstrong AJ, Rathkopf DE, Loriot Y, Sternberg CN, Higano CS, Iversen P, Bhattacharya S, Carles J, Chowdhury S, et al: Enzalutamide in metastatic prostate cancer before chemotherapy. N Engl J Med 371: 424-433, 2014.

9. Kim YS, Yi BR, Kim NH and Choi KC: Role of the epithelial-mesenchymal transition and its effects on embryonic stem cells. Exp Mol Med 46: e108, 2014.

10. Yang AD, Fan F, Camp ER, van Buren G, Liu W, Somcio R, Gray MJ, Cheng H, Hoff PM and Ellis LM: Chronic oxaliplatin resistance induces epithelial-to-mesenchymal transition in colorectal cancer cell lines. Clin Cancer Res 12: 4147-4153, 2006.

11. Kajiyama H, Shibata K, Terauchi M, Yamashita M, Ino K, Nawa A and Kikkawa F: Chemoresistance to paclitaxel induces epithelial-mesenchymal transition and enhances metastatic potential for epithelial ovarian carcinoma cells. Int J Oncol 31: 277-283, 2007.

12. Jennbacken K, Gustavsson H, Welén K, Vallbo C and Damber JE: Prostate cancer progression into androgen independency is associated with alterations in cell adhesion and invasivity. Prostate 66: 1631-1640, 2006.

13. Heerboth S, Housman G, Leary M, Longacre M, Byler S, Lapinska K, Willbanks A and Sarkar S: EMT and tumor metastasis. Clin Transl Med 4: 6, 2015.

14. Vesuna F, van Diest P, Chen JH and Raman V: Twist is a transcriptional repressor of E-cadherin gene expression in breast cancer. Biochem Biophys Res Commun 367: 235-241, 2008.

15. Vered M, Dayan D, Yahalom R, Dobriyan A, Barshack I, Bello IO, Kantola S and Salo T: Cancer-associated fibroblasts and epithelial-mesenchymal transition in metastatic oral tongue squamous cell carcinoma. Int J Cancer 127: 1356-1362, 2010.

16. Randle DD, Clarke S, Henderson V and Odero-Marah VA: Snail mediates invasion through uPA/uPAR and the MAPK signaling pathway in prostate cancer cells. Oncol Lett 6: 1767-1773, 2013.

17. Uygur B and Wu WS: SLUG promotes prostate cancer cell migration and invasion via CXCR4/CXCL12 axis. Mol Cancer 10: 139, 2011.

18. Navarro P, Ruco L and Dejana E: Differential localization of VE- and N-cadherins in human endothelial cells: VE-cadherin competes with $\mathrm{N}$-cadherin for junctional localization. J Cell Biol 140: 1475-1484, 1998.

19. Hatta K, Takagi S, Fujisawa $\mathrm{H}$ and Takeichi M: Spatial and temporal expression pattern of $\mathrm{N}$-cadherin cell adhesion molecules correlated with morphogenetic processes of chicken embryos. Dev Biol 120: 215-227, 1987.

20. Derycke LD and Bracke ME: N-cadherin in the spotlight of cell-cell adhesion, differentiation, embryogenesis, invasion and signalling. Int J Dev Biol 48: 463-476, 2004.

21. Ma T, Zhao Y, Wei K, Yao G, Pan C, Liu B, Xia Y, He Z, Qi X, Li Z, et al: MicroRNA-124 functions as a tumor suppressor by regulating $\mathrm{CDH} 2$ and epithelial-mesenchymal transition in nonsmall cell lung cancer. Cell Physiol Biochem 38: 1563-1574, 2016.

22. van der Horst G, Bos L, van der Mark M, Cheung H, Heckmann B, Clément-Lacroix P, Lorenzon G, Pelger RC, Bevers RF and van der Pluijm G: Targeting of alpha-v integrins reduces malignancy of bladder carcinoma. PLoS One 9: e108464, 2014.

23. Markou A, Lazaridou M, Paraskevopoulos P, Chen S, Świerczewska M, Budna J, Kuske A, Gorges TM, Joosse SA, Kroneis T, et al: Multiplex gene expression profiling of in vivo isolated circulating tumor cells in high-risk prostate cancer patients. Clin Chem 64: 297-306, 2018. 
24. Sandig M, Voura EB, Kalnins VI and Siu CH: Role of cadherins in the transendothelial migration of melanoma cells in culture. Cell Motil Cytoskeleton 38: 351-364, 1997.

25. Tanaka H, Kono E, Tran CP, Miyazaki H, Yamashiro J, Shimomura T, Fazli L, Wada R, Huang J, Vessella RL, et al: Monoclonal antibody targeting of $\mathrm{N}$-cadherin inhibits prostate cancer growth, metastasis and castration resistance. Nat Med 16: $1414-1420,2010$

26. Tomita K, van Bokhoven A, van Leenders GJ, Ruijter ET, Jansen CF, Bussemakers MJ and Schalken JA: Cadherin switching in human prostate cancer progression. Cancer Res 60: 3650-3654, 2000.

27. Jaggi M, Nazemi T, Abrahams NA, Baker JJ, Galich A, Smith LM and Balaji KC: N-cadherin switching occurs in high gleason grade prostate cancer. Prostate 66: 193-199, 2006.

28. Kregel S, Chen JL, Tom W, Krishnan V, Kach J, Brechka H, Fessenden TB, Isikbay M, Paner GP, Szmulewitz RZ and Griend DJV: Acquired resistance to the second-generation androgen receptor antagonist enzalutamide in castration-resistant prostate cancer. Oncotarget 7: 26259-26274, 2016.

29. Lee GT, Rosenfeld JA, Kim WT, Kwon YS, Palapattu G, Mehra R, Kim WJ and Kim IY: TCF4 induces enzalutamide resistance via neuroendocrine differentiation in prostate cancer. PLoS One 14 e0213488, 2019

30. Pangestu NS, Chueakwon P, Talabnin K, Khiaowichit J and Talabnin C: RNF43 overexpression attenuates the wnt/ $\beta$-catenin signalling pathway to suppress tumour progression in cholangiocarcinoma. Oncol Lett 22: 846, 2021.

31. Huang YH, Kuo HC, Yang YL and Wang FS: MicroRNA-29a is a key regulon that regulates BRD4 and mitigates liver fibrosis in mice by inhibiting hepatic stellate cell activation. Int $\mathbf{J}$ Med Sci 16: 212-220, 2019.

32. Bussemakers MJ, Van Bokhoven A, Tomita K, Jansen CF and Schalken JA: Complex cadherin expression in human prostate cancer cells. Int J Cancer 85: 446-450, 2000.

33. Jennbacken K, Tesan T, Wang W, Gustavsson H, Damber JE and Welén $\mathrm{K}$ : N-cadherin increases after androgen deprivation and is associated with metastasis in prostate cancer. Endocr Relat Cancer 17: 469-479, 2010.

34. Nalla AK, Estes N, Patel J and Rao JS: N-cadherin mediates angiogenesis by regulating monocyte chemoattractant protein-1 expression via PI3K/Akt signaling in prostate cancer cells. Exp Cell Res 317: 2512-2521, 2011.

35. Gao S, Zhao Z, Wu R, Wu L, Tian X and Zhang Z: MicroRNA-194 regulates cell viability and apoptosis by targeting $\mathrm{CDH} 2$ in prostatic cancer. Onco Targets Ther 11: 4837-4844, 2018.

36. Wang M, Ren D, Guo W, Huang S, Wang Z, Li Q, Du H, Song L and Peng X: N-cadherin promotes epithelial-mesenchymal transition and cancer stem cell-like traits via ErbB signaling in prostate cancer cells. Int J Oncol 48: 595-606, 2016.

37. Mariotti A, Perotti A, Sessa C and Rüegg C: N-cadherin as a therapeutic target in cancer. Expert Opin Investig Drugs 16: 451-465, 2007.

38. Tsai JH and Yang J: Epithelial-mesenchymal plasticity in carcinoma metastasis. Genes Dev 27: 2192-2206, 2013.
39. Loh CY, Chai JY, Tang TF, Wong WF, Sethi G, Shanmugam MK, Chong PP and Looi CY: The E-cadherin and N-cadherin switch in epithelial-to-mesenchymal transition: Signaling, therapeutic implications, and challenges. Cells 8: 1118, 2019.

40. Jiang YG, Luo Y, He DL, Li X, Zhang LL, Peng T, Li MC and Lin YH: Role of Wnt/beta-catenin signaling pathway in epithelial-mesenchymal transition of human prostate cancer induced by hypoxia-inducible factor-1alpha. Int J Urol 14: 1034-1039, 2007.

41. Chang L, Graham PH, Hao J, Ni J, Bucci J, Cozzi PJ, Kearsley JH and Li Y: Acquisition of epithelial-mesenchymal transition and cancer stem cell phenotypes is associated with activation of the $\mathrm{PI} 3 \mathrm{~K} / \mathrm{Akt} / \mathrm{mTOR}$ pathway in prostate cancer radioresistance. Cell Death Dis 4: e875, 2013.

42. Liang J, Li Y, Daniels G, Sfanos K, De Marzo A, Wei J, Li X, Chen W, Wang J, Zhong X, et al: LEF1 targeting EMT in prostate cancer invasion is regulated by miR-34a. Mol Cancer Res 13: 681-688, 2015.

43. Chen X, Cheng H, Pan T, Liu Y, Su Y, Ren C, Huang D, Zha X and Liang C: mTOR regulate EMT through RhoA and Racl pathway in prostate cancer. Mol Carcinog 54: 1086-1095, 2015.

44. Baygi ME, Soheili ZS, Essmann F, Deezagi A, Engers R, Goering W and Schulz WA: Slug/SNAI2 regulates cell proliferation and invasiveness of metastatic prostate cancer cell lines. Tumour Biol 31: 297-307, 2010.

45. Stylianou N, Lehman ML, Wang C, Fard AT, Rockstroh A, Fazli L, Jovanovic L, Ward M, Sadowski MC, Kashyap AS, et al: A molecular portrait of epithelial-mesenchymal plasticity in prostate cancer associated with clinical outcome. Oncogene 38: 913-934, 2019.

46. Li J, Chong T, Wang Z, Chen H, Li H, Cao J, Zhang P and $\mathrm{Li} \mathrm{H}$ : A novel anti-cancer effect of resveratrol: Reversal of epithelial-mesenchymal transition in prostate cancer cells. Mol Med Rep 10: 1717-1724, 2014

47. Du Y, Long Q, Zhang L, Shi Y, Liu X, Li X, Guan B, Tian Y, Wang X, Li L and He D: Curcumin inhibits cancer-associated fibroblast-driven prostate cancer invasion through MAOA/mTOR/HIF-1 $\alpha$ signaling. Int J Oncol 47: 2064-2072, 2015.

48. Vanacore D, Boccellino M, Rossetti S, Cavaliere C, D'Aniello C, Di Franco R, Romano FJ, Montanari M, La Mantia E, Piscitelli R, et al: Micrornas in prostate cancer: An overview. Oncotarget 8: 50240-50251, 2017.

49. Lo UG, Yang D and Hsieh JT: The role of microRNAs in prostate cancer progression. Transl Androl Urol 2: 228-241, 2013.

50. Cochetti G, Rossi de Vermandois JA, Maulà V, Giulietti M, Cecati M, Del Zingaro M, Cagnani R, Suvieri C, Paladini A and Mearini E: Role of miRNAs in prostate cancer: Do we really know everything? Urol Oncol 38: 623-635, 2020.

This work is licensed under a Creative Commons Attribution-NonCommercial-NoDerivatives 4.0 International (CC BY-NC-ND 4.0) License. 